\title{
Unmet Need and its Reasons for Nonuse Contraceptive in East Java Province
}

\author{
Diyah Herowati $^{1}$, Dwi Listyawardani ${ }^{1}$, Titut Yuli Prihyugiarto ${ }^{2}$ \\ ${ }^{1}$ East Java Provincial BKKBN \\ ${ }^{2}$ Research Center of Family Planning and Family Welfare BKKBN
}

\begin{tabular}{l}
\hline Article Info \\
\hline Article history: \\
Received Jun 12, 2016 \\
Revised Aug 18, 2016 \\
Accepted Aug 26, 2016 \\
\hline
\end{tabular}

\section{Keyword:}

Discontinuation

Reasons for Nonuse

Contraceptive

Unmet Need

\begin{abstract}
The primary aim of family planning program is to enable women to fulfill their own needs and desires toward childbearing whether they want to space or limit their birth. However, issues of unmet need in Indonesia, particularly in East Java Province become the urgent problem to be address recently. Based on the data set of the 2014 Mini Survey of Eligible couple in Indonesia, this study attempted to identify the demographic characteristic of women aged $15-49$ with unmet need, to describe their experienced used contraceptive and to find out reasons for nonuse of contraceptive. This study found that women with unmet need are more likely to be higher among older women, have lower and higher level of education, living in urban areas, and have more number of living children. Most of respondents stated that they had experienced to use contraception before with injectable, IUDs and pill. Other results show a significant number of women mentioned method-related reasons (fear of side effects, health concerns, and inconvenient to use) as most often cited reasons for nonuse. Some important policy implications offered from this study in order to eradicate barriers to the use of contraceptive methods are to improve follow-up, strengthen counselling approaches to address fear of side effects, promote information, education and communication (IEC) on reproductive health and provide availability of the most suitable method according to the need, such as to avoid health problems of women.
\end{abstract}

Copyright $(2016$ Institute of Advanced Engineering and Science. All rights reserved.

\section{Corresponding Author:}

Diyah Herowati,

BKKBN,

East Java Province, Indonesia,

Jalan Kalibokor Timur No. 1 Surabaya.

Email: didihero@yahoo.com

\section{INTRODUCTION}

Bradley, et al. [1] defined unmet need as the proportion of women who are not currently using a contraceptive method, but they want to delay a pregnancy and to stop childbearing. Refer to that definition, this study defined women in unmet need as the married women aged 15-49 who are not currently using a method of contraception but want to have child later (unmet need for spacing) and do not want any children (unmet need for limiting).

Unmet need become emerged issues replacing fertility reduction in the 1994 International Conference on Population and Development (ICPD). It has become a key indicator to evaluate the progress of family planning programs. Furthermore in 2007, it was strengthened as a indicator to measure the progress toward Millennium Development Goal (MDG) 5b, which is the achievement of universal access to reproductive health [2]. London Summit on Family Planning in 2012 declared that the primary goal of FP2020 was reducing unmet need [3]. 
Thus, meeting the need is not only to decline fertility rate, but also can assure the wellbeing of married women by preventing unwanted pregnancies. In turn it can decrease maternal mortality by reducing the number of pregnancies, abortions, and the proportion of births at risk [4]. In Indonesia, the improvement of the access to the service and its quality related to the unmet need has been the concern of the government.

With a total population of 37.5 million people, East Java is the second largest province in Indonesia. Based on 2010 Indonesia Population Census, the annual population growth rate was 0.76 percent per annum. Table 1 present the demographic indicators according to result of the Indonesia Demographic and Health Survey (IDHS). There has been an increase in contraceptive prevalence (CPR) from 55.4 percent in 1991 to 65.3 in 2012 [5]. During that period, however, the total fertility rate (TFR) has remained essentially constant, which were 2.1 and 2.3. Another more urgent concern is that issue associated with continuing unmet need. Based on IDHS, for a decade the family planning unmet need in East Java province increased steadily particularly from 5.6 in 2003, then 8.2 in 2007 and 10.1 in 2012 (Table 1). Among the 10.1 percent of total unmet need, 3.5 percent have an unmet need for spacing and 6.6 percent an unmet need for limiting [5].

It is in this context of increasing contraceptive prevalence to satisfying unmet need, the present study was carried out to identify the characteristics of unmet need for family planning in East Java Province in 2014. The study also attempts to examine factors associated with unmet need for family planning, mainly on reasons for nonuse contraception. Although some studies of unmet need have been done in Indonesia, not much known about the major reasons why women having unmet need are not practicing contraception, particularly in East Java Province.

Table 1. FP Indicators in East Java Province Based on Demographic and Health Survey (IDHS)

\begin{tabular}{lcccccc}
\hline \multicolumn{1}{c}{ INDICATORS } & \multicolumn{4}{c}{ Indonesia Demographic and Health Survey (IDHS) } \\
& 1991 & 1994 & 1997 & $2002 / 2003$ & 2007 & 2012 \\
\hline T F R & 2.13 & 2.22 & 2.33 & 2.1 & 1.9 & 2.3 \\
C P R & 55.4 & 55.9 & 61.1 & 67.0 & 66.1 & 65.3 \\
Unmet need & 10.0 & 9.0 & 7.6 & 5.6 & 8.2 & 10.1 \\
Median age of first marriage of women & 16.9 & 16.7 & 17.4 & 18.8 & 18.8 & 19.4 \\
Ideal number of children & 2.5 & 2.5 & 2.5 & 2.4 & 2.3 & 2.4 \\
\hline
\end{tabular}

Source: IDHS 1991, 1994, 1997, 2003, 2007 and 2012

\section{RESEARCH METHOD}

The data for analysis employed from the data set of the 2014 Mini Survey of eligible couple in Indonesia. This survey conducted annually by Population and Family Planning Board collaborated with Indonesia Central Board Statistic since the year of 2003. The samples are representative both nationally and provincially. In 2014, the survey was carried among 2,724 women of reproductive age (15-49 years) in East Java Province. Meanwhile this study filtered to yield 201 women between ages $15-49$, consist of 27 women who are either wish to postpone the next birth at least for next 2 years (for spacing) and 174 women who wish to stop child bearing (for limiting) but are not using a contraceptive method.

The technique of analysis employed mainly cross tabulation in order to identify and examine factors underlying of the incidence unmet need for spacing, unmet need for limiting and total unmet need separately. The descriptive analysis includes calculating the proportions of currently married women who want to space or limit childbearing and the proportion of unmet need for family planning.

\section{RESULTS AND ANALYSIS}

\subsection{Characteristics of unmet need for family planning}

Since the shifting focus on addressing the progress of family planning program, unmet need for family planning among married women has become a global issue in the world, and the prevalence was found higher in the developing countries [6]. This section presents the result of cross tabulation and discuss about the characteristic of unmet need for family planning. Table 2 shows the characteristics of unmet need, which consist of age group, level of education attainment, place of residence, and number of living children.

As shown in Table 2, the total unmet need for family planning in East Java Province is 7 percent, and currently married women age 15-49 are more likely to have an unmet need for limiting ( 6 percent) than for spacing (1 percent). Result showed that women having unmet need both for spacing and limiting started at age 25. Total unmet need rises with age, and reaching the peak at 13 percent among currently married women age 45-49. As expected, unmet need for spacing is more common among women who are younger. Meanwhile, unmet need for limiting increases rapidly among women aged 40 and older from 7 percent of 
women aged 35 - 39 to 12 percent of those aged 40 - 44. This finding is in the line with study by Misnaniarti, and Ayuningtyas, D. (2016) [7], that found amount of unmet need increased in accordance with age, the highest was for married women over 45 years old and almost all of unmet need on women under 25 years old was intended for spacing. Meanwhile unmet need for limiting increased on women aged 35 or more.

From this finding of the study it is evident that the age of women are not influencing unmet need for contraception of the currently married women. The association between total unmet need for family planning and respondent's age revealed that total unmet need increased as the age of the respondent increases. The possible explanation is that young age group has greater chance to seek access for family planning services and information; in contrast the old age group tends to find difficulties to implement their contraceptive intentions. The old age group mostly cites infrequent sex as they assumed not being fecund anymore. This is because they do not have enough information on reproductive health which is not using contraception during the reproductive age has higher risk to become pregnant. There are only 19 percent women who are not practicing the rhythm method know exactly when woman's fertile period occurs [8].

Table 2. Characteristics of Married Women aged 15-49 having Unmet Need by Selected Socio-demographic Status, East Java, 2014

\begin{tabular}{|c|c|c|c|c|c|c|c|}
\hline \multirow{2}{*}{$\begin{array}{l}\text { Background } \\
\text { Characteristic }\end{array}$} & \multicolumn{4}{|c|}{ Unmet need for family planning } & \multicolumn{2}{|c|}{ No Unmet Need } & \multirow{2}{*}{$\begin{array}{c}\text { All } \\
\text { Women }\end{array}$} \\
\hline & $\begin{array}{c}\text { For } \\
\text { spacing }\end{array}$ & $\begin{array}{c}\text { For } \\
\text { limiting }\end{array}$ & Total & $\begin{array}{l}\text { Number } \\
\text { of women }\end{array}$ & $\%$ & $\mathrm{~N}$ & \\
\hline \multicolumn{8}{|l|}{ Age group } \\
\hline $15-19$ & - & - & - & - & 100.0 & 36 & 36 \\
\hline $20-24$ & - & - & - & - & 100.0 & 191 & 191 \\
\hline $25-29$ & 1.3 & 0.5 & 1.8 & 7 & 98.2 & 374 & 381 \\
\hline $30-34$ & 1.4 & 3.6 & 5.2 & 29 & 94.8 & 530 & 559 \\
\hline $35-39$ & 1.7 & 5.2 & 6.9 & 36 & 93.1 & 488 & 524 \\
\hline $40-44$ & 0.7 & 11.3 & 12.2 & 67 & 87.8 & 481 & 548 \\
\hline $45-49$ & 0.2 & 12.8 & 13.0 & 63 & 87.0 & 422 & 485 \\
\hline \multicolumn{8}{|l|}{ Education } \\
\hline No education & - & 10.0 & 10.0 & 9 & 90.0 & 81 & 90 \\
\hline Some primary & - & 7.0 & 7.0 & 22 & 93.0 & 293 & 315 \\
\hline Completed primary & 0.7 & 4.5 & 5.2 & 39 & 94.8 & 712 & 751 \\
\hline Completed secondary & 1.1 & 5.7 & 6.6 & 41 & 93.4 & 576 & 617 \\
\hline Competed tertiary & 1.3 & 7.8 & 9.2 & 68 & 90.8 & 673 & 741 \\
\hline More than tertiary & 2.9 & 7.2 & 10.0 & 21 & 90.0 & 188 & 209 \\
\hline \multicolumn{8}{|l|}{ Residence } \\
\hline Urban & 1.2 & 7.4 & 8.7 & 98 & 91.3 & 1034 & 1132 \\
\hline Rural & 0.9 & 5.6 & 6.5 & 103 & 93.5 & 1489 & 1592 \\
\hline \multicolumn{8}{|l|}{ Number of living children } \\
\hline 0 & 0.6 & 1.2 & 1.8 & 3 & 98.2 & 160 & 163 \\
\hline 1 & 1.3 & 2.0 & 3.3 & 31 & 96.7 & 909 & 940 \\
\hline 2 & 1.1 & 8.2 & 9.3 & 102 & 90.7 & 996 & 1098 \\
\hline 3 & 0.8 & 11.7 & 12.5 & 47 & 87.5 & 330 & 377 \\
\hline $4+$ & - & 12.3 & 12.3 & 18 & 87.7 & 128 & 146 \\
\hline Total & 1.0 & 6.4 & 7.4 & 201 & 92.6 & 2523 & 2724 \\
\hline
\end{tabular}

Source: computed from the 2014 Indonesia Mini Survey of Eligible Couple data tape

Regarding their educational status, study found total unmet need in East Java tend to be higher among women with less and better education, which is women with no education and more than tertiary were 2 times more likely to experience unmet need for family planning compared to those with completed primary (10 percent compared to 5 percent). The relatively same trend followed with unmet need for limiting, which is higher among less and better educated. Meanwhile, unmet need for spacing increased slightly with level of education, the more educated women, the higher prevalence of unmet need. Three percent of women with more than tertiary were unable to meet their demand for spacing compared to 1 percent of those who had completed primary.

Many studies found, women's education plays an important role to influence level of unmet need for family planning. The possible explanation is that educated women are well informed about the various methods of contraceptive as they tend be easier access to media and information. Result of IDHS 2012 showed that almost all women (99.5 percent) who had more than secondary in East Java Province have heard of at least one modern method. They also have greater access to family planning services, such as the availability of contraceptive methods and family planning providers [9],[10]. Since the study also found that well educated also have high proportion of unmet need, this indicates that even they are well educated but less likely to get the information about side effects, as they cited side effects as the main reason for nonuse contraceptive. 
Even there was not much different by place of residence, surprisingly, women who living in urban areas had the higher proportion of total unmet need, unmet need for spacing, and unmet need for limiting than their rural counterparts (9 percent versus 7 percent). This finding similar with the result of Eleanor's research, which was the geographical distance to family planning services, is not the major obstacle to the contraceptive use [11]. In contrast, Study by Genet in Dangila town, Ethiopia, (2015) [12], found that the level of unmet need for FP among rural residents was twice as high as the level among urban residents. This because women in rural area have lower level of awareness on family planning and educational status.

Unmet need for limiting was more commonly observed among women who had two and more children, the prevalence increased rapidly among women with 3 children, peaking at 12 percent among women who had 4 and more children. On the other hand, unmet need for spacing does not vary across number of living children. One percent of women had no child and having 1 to 3 children stated not using contraceptive even they want to have more children later.

\subsection{Past use contraception}

To all observed women with unmet need at the time of survey were asked whether they have ever used modern contraception in the past or never, what modern method they ever used and why they stop using contraceptive. This purpose to know to what extend they adopt family planning program before. Table 3 presents the experience of married women age 15-49 with unmet need on family planning practice at past, methods ever used and reasons for contraceptive discontinuation. Among the total number of 201 unmet need, there was 70 percent unmet need who had ever used contraceptive method and 30 percent had never used any method before. Never use any modern contraceptive much higher among unmet need for spacing than for limiting (37 percent versus 29 percent). The most recent contraceptive method ever used by women with unmet need primary was injectable (55 percent) followed by intrauterine device (IUD), and pill about 19 percent. If injectable and pill were more common used among spacer unmet need, injectable and IUD dominated methods among the limiters (77 percent). Looking at the condom and implant were less cited (below 10 percent) being used by unmet need women both for spacing and limiting.

\subsection{Reason for discontinuation}

Contraceptive discontinuation leads to increase in the level unmet need for family planning. Gaining a better understanding of the types of women who are likely to experience dropout for contraception will be potential in providing policy implication to address the barriers to family planning service. Recent study by Gilda S. and Rubina H. (2014) found that the most common reasons for contraceptive non-use in many developing countries are infrequent sexual activity, concern about side effect and health problems [13].

Of those currently married women who are unmet need and had experienced on family planning practice, were asked what the main reason for stopping contraceptive use. For almost half (44 percent) of total unmet need, women stopped using contraception because of fear about side effects (Table 3). The same pattern have been shown for unmet need both for spacing and limiting, which was fear of side effect become most dominant reason of discontinuation (24 percent for spacer and 46 percent for limiters). The next most common reason for discontinuation given was about health concerns (16 percent). Gilda Sedgh and Rubina Hussain (2014) state that women who express concerns regarding side effects and health risks associated with method use might be expected to have based their rationale on prior experience using modern contraceptives [13]. Meanwhile in East Java Province, 9 percent of women cited inconvenient to use and infrequent sex as reasons for contraceptive discontinuation.

The most prominent reason for discontinuation among unmet need for limiting was side effect (46 percent), meanwhile side effect and desired to become pregnant ( 24 percent) were the most frequent reason for discontinue their use among unmet need for spacing. Furthermore, spacers more likely had experienced husband/parent/anyone disapproved than limiters (12 percent versus 2 percent). Unlike unmet need for spacing who never experienced facing health concern, 19 percent women who want to stop childbearing was reported to discontinue using contraceptive due to health concerns. In contrast, husband away found to be higher among unmet need for spacing (6 percent) than limiting.

One of strategy maintaining continuity of contraceptive use is by promoting long term contraceptive method. However study found, the percentage of discontinuations because women wanted a more effective method was only under 3 percent. 
Table 3. Unmet Need by Family Planning Practiced at Past,Methods and Reasons for Discontinuation, East Java, 2014

\begin{tabular}{|c|c|c|c|c|}
\hline \multirow{2}{*}{ Ever used/method/reasons } & \multicolumn{3}{|c|}{ Unmet need for family planning } & \multirow{2}{*}{$\begin{array}{l}\text { Number } \\
\text { of women }\end{array}$} \\
\hline & For spacing & For Limiting & Total & \\
\hline \multicolumn{5}{|l|}{ Ever used modern contraceptive } \\
\hline Yes & 63.0 & 71.1 & 69.7 & 140 \\
\hline No & 37.0 & 28.9 & 30.3 & 61 \\
\hline $\mathrm{N}$ & & & & 201 \\
\hline \multicolumn{5}{|l|}{ Methods have ever used } \\
\hline IUD & 11.8 & 20.2 & 19.3 & 27 \\
\hline Implants & 5.9 & 6.5 & 6.4 & 9 \\
\hline Injectable & 41.2 & 56.5 & 55.0 & 77 \\
\hline Pill & 41.2 & 16.1 & 18.6 & 26 \\
\hline Condom & 0.0 & 0.8 & 0.7 & 1 \\
\hline $\mathrm{N}$ & & & & 140 \\
\hline \multicolumn{5}{|l|}{ Reasons for discontinuation } \\
\hline Infrequent sex & 11.8 & 8.1 & 8.5 & 12 \\
\hline Husband away & 5.9 & 0.1 & 1.4 & 2 \\
\hline Declared in fecund & 0.0 & 4.1 & 3.5 & 5 \\
\hline Husband/parent/anyone opposed & 11.8 & 1.6 & 2.8 & 4 \\
\hline Health concerns & 0.0 & 18.7 & 16.3 & 23 \\
\hline Side effect & 23.5 & 46.3 & 44.0 & 62 \\
\hline Lack of access/too far & 0.0 & 0.8 & 0.7 & 1 \\
\hline Cost too much & 0.0 & 0.8 & 0.7 & 1 \\
\hline Inconvenient to use & 17.6 & 8.1 & 9.2 & 13 \\
\hline Pregnant & 0.0 & 0.8 & 0.7 & 1 \\
\hline Desired to become pregnant & 23.5 & 2.4 & 5.0 & 7 \\
\hline Wanted a more effective method & 0.0 & 1.6 & 1.4 & 2 \\
\hline IUD expelled & 0.0 & 0.8 & 0.7 & 1 \\
\hline Other & 5.9 & 4.9 & 5.0 & 7 \\
\hline $\mathrm{N}$ & 17 & 123 & - & 140 \\
\hline
\end{tabular}

Source: computed from the 2014 Indonesia Mini Survey of Eligible Couple data tape

\subsection{Reasons for nonuse contraception}

One way to identify the barriers of the adoption family planning is asking the women who wish to postpone the next birth (spacing) and to stop childbearing (limiting) but not using contraceptive why they do not use contraceptive. Table 4 present the main reasons for not practicing contraceptive among women having unmet need. About fourth-fifth of women mentioned method related reasons as the reason for non use, which were side effects ( 37 percent), health concerns (22 percent) and inconvenient to use (18 percent). Furthermore, the percentage of women being unmet need due to fertility-related reasons was 11 percent, especially women who stated infrequent sex as their reason non-use.

The three major reasons for nonuse contraceptive cited by spacer were fear of side effect (31 percent), inconvenient use ( 27 percent) and husband/parent/anyone opposed (15 percent). Meanwhile limiters most express about side effect (37 percent), health concerns ( 24 percent) and inconvenient to use (16 percent) as reasons for contraceptive nonuse.

Compared to the unmet need for limiting, inconvenient to use cited more often by the women with spacing unmet need which is the second reason for nonuse among them ( 27 percent versus 16 percent).

Health concerns in this study is defined a condition regarding health status of respondent, such as do they suffer from hypertension/high blood pressure, heart problems, varices, and liver diseases. This study found health concerns mostly experienced by women aged $40-49$ years old with injectable as a method that they ever used before. In the line with many research finding documented by Gilda Sedgh and Rubina Hussain, 2014, which showed that side effects and health risks are especially common among women who have previously used injectable, IUDs, and oral contraception.

Study of Eleanor, 2012, explored that fear of side effects associate with non-use mainly because they do not understand enough about contraceptive method, they are not educated about the side effect, so they are worried it might affect their health [11]. In east Java Province, the observed women mentioned side effects reason that cause they are not using contraception because mostly have experienced using a certain contraceptive method (injectable) before. Meanwhile Eleanor (2012), found in some cases a method had been tried and then discontinued due to the women experiencing side effects, but in many cases the method had not been tried of the fear that they would experience a problem [11]. 
Table 4. Reasons for Nonuse Contraceptive among Women Aged 15-49 Having Unmet need, East Java, 2014

\begin{tabular}{lcccc}
\multicolumn{1}{c}{ Reasons for Nonuse Contraceptive } & $\begin{array}{c}\text { For } \\
\text { spacing }\end{array}$ & $\begin{array}{c}\text { For } \\
\text { limiting }\end{array}$ & $\begin{array}{c}\text { Total Unmet } \\
\text { Need }\end{array}$ & $\begin{array}{c}\text { Number } \\
\text { of women }\end{array}$ \\
\hline Fertility-related reasons & 11.5 & 10.9 & 11.0 & 22 \\
$\quad$ - Infrequent sex & 7.7 & 10.3 & 10.0 & 20 \\
- Pregnant & 3.8 & 0.6 & 1.0 & 2 \\
Opposition to use & 19.2 & 5.2 & 7.0 & 14 \\
- Husband/parent/anyone opposed & 15.4 & 2.9 & 4.5 & 9 \\
- Culture and religious belief against & 3.8 & 2.3 & 2.5 & 5 \\
$\quad$ contraception & & & \\
Method-related reasons & 65.4 & 81.6 & 79.5 & 155 \\
- Health concerns & 7.7 & 24.1 & 22.0 & 44 \\
- Side effect & 30.8 & 37.4 & 36.5 & 73 \\
- Lack of access/too far & - & 1.1 & 1.0 & 2 \\
- Cost too much & - & 2.9 & 2.5 & 5 \\
- Inconvenient to use & 26.9 & 16.1 & 17.5 & 5 \\
Other reasons & 3.8 & 2.3 & 2.5 & 35 \\
Total & 100 & 100 & 100 & 5 \\
\hline
\end{tabular}

Source: computed from the 2014 Indonesia Mini Survey of Eligible Couple data tape

\section{CONCLUSION AND SUGGESTION}

The unmet need for modern contraception reported in this study is revealed that total unmet need increased as the age of the respondent and number of living children increases and there was no associate between place of residence and unmet need. Most of unmet need experienced to used contraceptive method before, which were injectable and pill were more common used among spacer unmet need, meanwhile injectable and IUD dominated methods among the limiters. There are two major reasons underlying non-use of contraceptive among unmet need women, which were side effects and health concerns.

With regards in these findings, some program intervention offered are to strengthen counselling approaches to address fear of side effects, improve follow-up, and encourage the most suitable method according to the need, such as to avoid health problems of women.

\section{ACKNOWLEDGEMENTS}

We would like to thank to colleagues from Center for Research and Development of Family Planning and Family Welfare Program for providing data set in this study.

\section{REFERENCES}

[1] S. E. K. Bradley, et al., "Revising Unmet Need For Family Planning, DHS Analytical Studies 25," United States Agency for International Development, 2012.

[2] J. Cleland, "Unmet Need for Contraception: Issues and Challenges," Studies in Family Planning, vol/issue: 45(2), pp. 105-122, 2014.

[3] I. Askew, M. Brady, "Reviewing the evidence and identifying gaps in family planning research: The unfinished agenda to meet FP2020 goals," background document for the Family Planning Research Donor Meeting, Washington, DC, 3-4 December 2012, New York, Population Council, 2013.

[4] G. Woldemicael, "Currently married women with an unmet need for contraception in Eritrea: Profile and determinants," Canadian Studies in Population, vol/issue: 38(1-2), pp. 61-81, 2011.

[5] National Population and Family Planning Board \& Statistics Indonesia, et al, "Indonesia Demographic and Health Survey 2012,” Jakarta, Indonesia, BPS, BKKBN, Kemenkes, and ICF International, 2013.

[6] S. A. Adebowale and M. E. Palamuleni, "Determinants of Unmet Need for Modern Contraception and Reasons for Non-use among Married Women in Rural Areas of Burkina Faso," African Population Studies, vol/issue: 28(1), 2014.

[7] Misnaniarti and D. Ayuningtyas, "Unmet need for family planning in Indonesia and the policy strategy of intervention in several countries," International Journal of Reproduction, Contraception, Obstetrics and Gynecology, vol/issue: 5(6), pp. 1680-1685, 2016.

[8] BKKBN, "Profil SDKI 2012 Provinsi Jawa Timur," Puslitbang KB dan KS, BKKBN, 2013.

[9] Assefa H., et al, "Factors Affecting Unmet Need for Family Planning in Southern Nations, Nationalities And Peoples Region, Ethiopia," Ethiop J Health Sci., vol/issue: 21(2), 2011.

[10] P. Kisaakye, "Determinants of Unmet Need For Contraception To Space And Limit Births Among Various Groups of Currently Married Women in Uganda," 1st Annual International Interdisciplinary Conference, AIIC 2013, 24-26 April, Azores, Portugal, 2013.

[11] E. F. Hukin, "Contraception in Cambodia, Explaining Unmet Need," A Thesis submitted to the Department of Social Policy at London School of Economic for the Degree of Doctor of Philosophy, London, 2012. 
[12] Genet, et al., "Determinants of unmet need for family planning among currently married women in Dangila town administration, Awi Zone, Amhara regional state; a cross sectional study," Reproductive Health, vol. 12, pp. 42, 2015.

[13] G. Sedgh and R. Hussain, "Reasons for Contraceptive Nonuse among Women Having Unmet Need for Contraception in Developing Countries," Studies in Family Planning, vol/issue: 45(2), pp. 151-169, 2014. 